\title{
A FICÇÃO DE CRIME EM AMOR CRUEL, AMOR VINGADOR, De MARia José de QUeIroz*
}

\author{
Crime fiction in Amor cruel, amor vingador, \\ by Maria José de Queiroz
}

\author{
Christini Roman de Lima ${ }^{1}$ (i) \\ ${ }^{1}$ Universidade Presbiteriana Mackenzie (UPM). São Paulo, SP, Brasil. \\ E-mail: christiniroman@gmail.com
}

EDITOR-CHEFE:

Gerson Roberto Neumann

EDITOR EXECUTIVO:

Regina Zilberman

SUBMETIDO: 30.04 .2021

ACEITO: 15.06 .2021

COMO CITAR:

LIMA, Christini Roman de. A Ficção de crime em Amor cruel, amor vingador, de Maria José de Queiroz. Revista Brasileira de Literatura Comparada,v.23,n.44,p.265-269, set.-dez., 2021. doi: https:// doi.org/10.1590/2596$304 \times 20212344 \mathrm{crl}$ http:// www.scielo.br/rblc https://revista.abralic.org.br

\footnotetext{
* Resenha de: QUEIROZ, Maria José de. Amor cruel, amor vingador. Belo Horizonte, Minas Gerais: Caravana Grupo Editorial, 2021.
} 
França e Sasse (2016) apontam que, antes do advento de Dupin ou de Sherlock Holmes, de Arthur Conan Doyle, a literatura de crime era muito popular na Inglaterra, sendo o Newgate Calendar a mais emblemática das suas publicações. Esse Calendar era, originalmente, constituído como um boletim da prisão de Newgate que continha informes sobre os novos prisioneiros, seus crimes, o procedimento da detenção, o julgamento e a punição estabelecida.

Essas narrativas, segundo os autores, poderiam ser vistas como antecessoras tanto da literatura policial, como também do romance de sensação britânico, uma vez que o núcleo narrativo consistia em um crime "frequentemente assassinato como uma consequência do adultério e, algumas vezes, da bigamia, nos aparentemente mais respeitáveis e burgueses ambientes domésticos” (BRANTLINGER, apud FRANÇA; SASSE, 2016, p. 81). Alessandra El Far (2004) destaca que, no Brasil, o termo "sensação" era muito utilizado no século XIX, aludindo a situações inesperadas e assustadoras. Segundo a autora, a literatura de sensação consistia em tramas conflituosas e com mortes violentas, crimes terríveis ou eventos imprevisíveis. Álvaro Lins (1954, p. 11) destaca que o romance policial provoca no leitor uma evasão, uma inversão de realidades em que o leitor adentra em um "universo de natureza anormal, o do crime", o qual apaixona os leitores não apenas pelo fora do comum, mas pela "ligação secreta com este mundo de horrores, operada nas circunstâncias de que no homem mais virtuoso ou tímido existe a possibilidade de praticar o ato anormal do criminoso".

Maria José de Queiroz (1996) aponta no prefácio “Leitor” que, nas histórias dos contos, “o amor e a morte impõem uma forma de vida, estabelecem a lógica interna dos relatos ao mesmo tempo que enovelam as tramas dos cinco enredos" (p. 13). Amor cruel, amor vingador é composto, portanto, por cinco contos: "O juramento", "Velho com mulher moça", "Iniciação ao Tratado do desespero", "Ritinha-Chiquê ou A hora do carvoeiro" e "A morte ao pé da letra”. Os enredos do livro de Queiroz trazem, dessa forma, sujeitos que são arrastados pelos excessos de seus sentimentos desmedidos. A autora destaca (p. 11) que:

Nas cinco histórias de amor cruel e amor vingador recolhidas neste pequeno volume (...) a vítima se converte em culpado ou vice-versa. Descobri ao epílogo de "A morte ao pé da letra", que a tragédia de Sófocles poderia servir de script, em sucessivas versões, ao projeto homicida ou suicida desse ou daquele protagonista. E tudo dependeria da identificação do leitor com seu duplo - o herói que lhe propiciasse a desejada catarse. (p. 13)

"O juramento" é o conto - ou, como a autora adverte, tendo como parâmetro o neologismo criado por Miguel de Unamuno, a "nivola” - que abre a compilação. Essa história é a mais longa do livro; narrada em terceira pessoa, ela aborda em seu entrecho o assassinato de uma viúva herdeira de um rico espólio. A trama converge em torno do homicídio, da investigação policial e de suas idas e vindas em torno do suspeito principal, o enteado da vítima, Raimundo Silva Guimarães - que não ficara satisfeito com a distribuição das propriedades feita pelo pai em testamento, principalmente sobre uma casa de campo de que a madrasta era a usufrutuária.

O segundo conto intitula-se "Velho com mulher moça". A narrativa autodiegética foca-se na história de um homem humilde, Antônio, que deixa a fazenda dos pais, em Bocaina (Minas Gerais), e testemunha o homicídio do dono do local em que pernoita. Depois de um mês trabalhando em uma fazenda próxima à localidade do crime, Antônio encontra um advogado que estava na região para o 
inquérito da morte de Raimundo Rodrigues, o idoso que fora assassinado. A coincidência leva Antônio a tornar-se testemunha do caso e a ajudar a desvendar a autoria e motivação do crime.

O conto que dá segmento ao livro é "Iniciação ao Tratado do desespero", e ele difere dos demais, porque não aborda um caso de crime e sua elucidação, mas um suicídio. A perspectiva abrange um "triângulo afetivo" formado por dois rapazes e a narradora do conto: Aluísio, Cláudio e Ruth. A amizade se desenvolve nos tempos da faculdade, nos anos de 1953, quando os jovens estavam envoltos pelo Existencialismo em voga e imersos, sobretudo, no filósofo "nebuloso" Kierkegaard: "foi ele que definitivamente nos uniu (...), fascinados que estávamos pelas suas lições de desespero e angústia” (p. 116). Os anos passaram, os amigos se distanciaram e não mais se viram, até Ruth ter a notícia de que Cláudio Sampaio tirara a própria vida. A narradora descobre que Cláudio não se conformara por não ter tido filhos e negara-se terminantemente à adoção. Um recém-nascido, no entanto, foi deixado na porta de sua casa em uma quinta-feira da Semana Santa. A criança chamava-se Aluísio. A esposa de Cláudio, Rosalva, levou o bebê ao juizado de menores e, concomitantemente, Cláudio "suicidou-se dentro da Igreja da Matriz de Belém do Pará, numa segunda-feira de Páscoa” (p. 120). A mulher, após a morte do marido, adotou uma menina a quem deu o nome de Ruth. Os filhos, mesmo que indesejados, repetiam os nomes dos amigos de outrora, mas o "triângulo afetivo" jamais se restituiu.

O quinto conto de Amor cruel, amor vingador é "Ritinha-Chiquê ou a hora do carvoeiro". A história é narrada por dois narradores homodiegéticos. A intriga concentra-se, portanto, em uma conversa sobre a morte de um carvoeiro pelas mãos de Ritinha, a Ritinha-Miséria. Expedito, o barbeiro da cidade, fala com Miguel Costa sobre o assassinato, enquanto escanhoa sua barba. Expedito comenta a condição social da personagem (era filha única de um fazendeiro do Alto-Paraíba, herdeira de muitos bens e propriedades) e como ela passou de menina educada em colégio interno de freiras a "beata maluca". Ele busca convencer o cliente de que o crime fora cometido, porque o homem tentara roubar Ritinha. Miguel Costa, de barba feita, toma a palavra e expõe a sua versão sobre o crime - falando de modo categórico: "Você só é mesmo expedito na navalha. Crime é comigo, barbeiro! Conto-lhe agora, o que, de fato, ocorreu, e como" (p. 128). A personagem assassinara o carvoeiro, porque, após manterem repetidas relações sexuais, ele se negara a continuar satisfazendo os desejos da "beata”. Ritinha teria matado o homem, assim, para impedir sua fuga. $\mathrm{O}$ conto, portanto, apresenta duas versões do crime, mas não se sabe qual exposição é mais confiável.

O último conto da coletânea é “A morte ao pé da letra”. A história é narrada em primeira pessoa por uma professora do Instituto de Estudos Portugueses e Brasileiros da Universidade Sorbonne e aborda a relação mantida entre essa narradora e um jovem pesquisador, Pierre Mouzon, a quem ela orientara no período e que, anos mais tarde, acabara cometendo uma atrocidade. A professora destaca que a relação de amizade e orientação se manteve mesmo depois de o jovem ter concluído seu doutorado, de estar estabelecido e, também, de ela ter retornado ao Brasil. Pierre dedicava-se a escrever uma nova versão de Antígona, peça que lia incansavelmente por telefone para a antiga orientadora. Ao final da tragédia reescrita, o jovem converte as personagens em pessoas que lhe eram próximas: “Creonte é meu pai, eu sou Hemom, Antígona é Mademoiselle Sebbar e Eurídice é minha mãe” (p. 136) - aspecto que, de certo modo, intrigou a ouvinte, mas que se desvaneceu entre os seus afazeres. Meses depois, no entanto, ela recebeu uma carta com a notícia da tragédia real ocorrida com Pierre e sua família: 
o pai morrera, suspeitando-se homicídio, e, pouco depois, o jovem matara a namorada e se suicidara. A representação literária, lida para a narradora, tornou-se script do ato final premeditado por Pierre.

Os contos do livro de Maria José de Queiroz estão envoltos, portanto, em assassinatos - ou suicídios -, mas apenas as duas primeiras histórias, sobretudo a "nivola" "O juramento", podem ser elencadas à literatura policial, uma vez que apresentam aspectos próprios ao gênero, tais como a figura do detetive e o mistério circunscrito ao crime e a sua resolução. Segundo Fernanda Massi (2011, p. 15), o detetive se estabeleceu como "figura principal e indispensável de qualquer narrativa" considerada policial. Não bastaria, no entanto, que o detetive figurasse como tema, ele teria de ser "o núcleo do enredo", o agente da investigação: "A investigação, portanto, deve existir a partir de um crime e, este, a partir de uma vítima e de um criminoso" (MASSI, 2011, p. 15). As demais tramas de Maria José de Queiroz, no entanto, enquadrar-se-iam na categoria mais ampla da ficção de crime.

Na literatura brasileira, conforme Julio França e Pedro Puro Sasse (2016), o protagonismo do detetive perde espaço para o do criminoso. Essa literatura em que o crime é o impulsionador da trama tem expoentes nas letras nacionais desde Memórias de um condenado e Mistério da Tijuca, de Aluísio Azevedo (publicados no início da década de 1880 e modificados em 1900 e 1901, o primeiro tornandose Girândola de amores, e o segundo, A condessa Vésper), passando pela literatura de sensação, tal como Elzira, a Morta Virgem, escrita por Pedro Ribeiro Vianna e publicada em 1883 (EL FAR, 2011) e chegando à literatura contemporânea com, por exemplo, O cobrador, de Rubem Fonseca, publicado em 1979, e com O matador, de Patrícia Melo, publicado em 1995.

A literatura policial, assim como a ficção de crime, passou, desse modo, de uma literatura considerada menor, a um gênero que se estabeleceu no mundo literário e que teve muitos autores consagrados aventurando-se por seus meandros (VILAS-BOAS, 2015). Maria José de Queiroz insere seu Amor cruel, amor vingador nesse índice de intrigas repletas de sensações surpreendentes e assombrosas; sensações essas que causam fascínio em leitores de todos os tempos.

\section{REFERÊNCIAS}

EL FAR, Alessandra. Páginas de sensação: literatura popular e pornográfica no Rio de Janeiro (1870-1924). São Paulo: Companhia das Letras, 2004.

EL FAR, Alessandra. Os romances de que o povo gosta: o universo das narrativas populares de finais do século XIX. Floema (Caderno de Teoria e História Literária), Ano VII, n. 9, p. 11-31, jul./dez. 2011. Disponível em: https://periodicos2.uesb.br/index.php/floema/article/view/1814. Acesso em: 18 ago 2021.

FRANÇA, Julio; SASSE Pedro Puro. O Fascínio do Crime: João do Rio e as Raízes da Literatura Policial no Brasil. In.: VIEGAS, Ana Cristina Coutinho; PONTES JR., Geraldo; MARQUES, Jorge Luiz (Orgs.). Configurações da Narrativa Policial. Rio de Janeiro: Dialogarts Publicações, 2016. Disponível em: http:// www.dialogarts.uerj.br/arquivos/livro_narrativa_policial.pdf\#page=71. Acesso em: 18 ago 2021.

LINS, Álvaro. No mundo do romance policial. São Paulo: Ministério da Educação e Saúde: Serviço de documentação, 1954. Disponível em: https://kupdf.net/download/alvaro-lins-no-mundo-do-romance-pol icial_59f3c846e2b6f5904e0cd51f_pdf. Acesso em: 19 ago 2021. 
MASSI, Fernanda. O romance policial do século XXI: manutenção, transgressão e inovação do gênero. São Paulo: Cultura Acadêmica, 2011. (Coleção PROPG Digital - UNESP). ISBN 9788579832130. Disponível em: http://hdl.handle.net/11449/109189. Acesso em: 18 ago 2021.

QUEIROZ, Maria José de. Amor cruel, amor vingador. Belo Horizonte, Minas Gerais: Caravana Grupo Editorial, 2021.

VILAS-BOAS, Gonçalo. O crime na literatura. Observatório: De África, América Latina e Caraíbas - Outras literaturas: Policial. Universidade do Porto: Repositório Aberto. Disponível em: https://repositorio-aberto. up.pt/bitstream/10216/78758/2/101272.pdf. Acesso em: 18 ago 2021. 